density, photogrammetry, measurements of time and fluid flow and the investigation of lapping techniques illustrates the breadth of the need for precise measurement and development in basic techniques.

In the general field of engineering dimensional metrology, assistance is given to industry by testing measuring equipment of all types, machine tools and workpieces, by advice on the design of precision measuring apparatus, and by providing practical help in the alignment of large-scale engineering structures. The air gauging technique is being applied to the development of special measuring equipment.

Other needs of the engineer receive the attention of the Applied Mechanics Section, which is responsible for the measurement of force (load), pressure and hardness, and conducts research in vibration, engineering design, production processes and the mechanical aspects of machining. This Section is equipped for the measurement of load up to 500 tons-force in compression and 50 tons-force in tension, for the measurement of hardness in the usual scales, and has deadweight pressure gauge testers ranging up to 30,000 pounds-force per square inch.

Particular attention has been paid to the factors governing the functional requirements of an engineering product in relation to production and inspection, and the results of analytical study of these factors are being widely disseminated by publication and lecturing. In parallel, and in support, research is being conducted to determine the factors in machining which control dimensional frequency distribution, tool wear and tool life.

A small but active Electronics Section has been busy applying electronic techniques to a variety of problems such as a pressure controller for barometry and the measurement of the periodic errors in machine tools and of cutting forces in research on machinability. It is to be expected that this Section will be expanded in due course in order to reap more fully the advantages in accuracy and flexibility which electronic techniques can bring to precise measurement.

Returning to the subject of vibration, it is recorded that the demand for vibration testing and consultative services have seriously reduced progress on main research projects and that certain of the Division's equipment has had to be moved to a site shown by a vibration survey to be less objectionable. The simultaneous growth of the need for more powerful machines and equipment and for greater refinement of measurement presents a growing problem of particular importance to all metrologists, a problem which will become increasingly difficult to solve without forethought on the part of all concerned.

The staff of about three dozen research officers and technical officers, helped by an equal number of technical assistants, during the year published nearly a dozen papers and had some half a dozen further papers ready for publication. Indicative of the high regard in which the work of the Division of Metrology is held is the recent appointment ${ }^{2}$ of its chief, Mr. N. A. Esserman, as the first director of the National Standards Laboratory. This is stated to be one of the first consequences of the recommendations made by a committee of the Advisory Council which reported last year on the future development of the Laboratory. Mr. Esserman remains directly responsible for the work of the Division.

1 Nature, 182, 291 (1958).

\title{
BRISTOL CITY MUSEUM
}

T THE report of the City of Bristol Museum for $1957 *$ continues the series of readable, wellproduced and attractively illustrated publications issued annually by that Museum, in which it also continues to record a commendable extension of activities and responsibilities, evidenced by the introductory matter on the personnel and scope of committees and sub-committees on general museum work, on staffing and policy, on the preservation of ancient Bristol and on the Museum School Service. The latter, for years an informal advisory committee, has now become fully official, reflecting the increased volume of, and value placed upon, the work the Museum does for the schools of the area. It is presided over by the chairman of the City Museum and Art Gallery Committee, and its members include teachers serving in Bristol schools and representatives of departments of education.

Staff matters reflect the health of any museum. In this report, loyalty and long service to a respected institution are reflected in the retirement of the administrative assistant after forty-five years service - thirty-three years of which were with the Museum and Art Gallery-and of the museum foreman after twenty-two years. One member of the staff has obtained an M.A. degree and another the diploma of the Museums Association, while a third has left to

- The City Museum, Bristol. Report of Committee for the year ended 31 December, 1957. Pp. 23. (Bristol : The City Museum, 1958.) take up a curatorial post in another institution. The director and staff also figure as officers or members of a variety of learned societies and advisory bodies, both national and local, and the list of research work accomplished and papers published is clear evidence of a busy institution.

The acquisition of Chatterton House, the birthplace of the boy-poet Thomas Chatterton, thanks to the generous intervention of the Dulverton Trust, adds to the many attractions Bristol Museum can offer. Temporary exhibitions continue to be a major offering to townspeople and visitors-a post-war feature of museums' activities, which take much time and give much trouble, but which are greatly worthwhile. The lenders range from the city librarian and city archivist to the Victoria and Albert Museum in London. Publications produced include a "Guide to Roman Buildings in Kings Weston Park" and leaflets on the Folk Museum at Blaise Castle House, as well as programmes of a highly successful series of winter lectures and summer conducted walks to places of historical or scientific interest in the neighbourhood. The services rendered are varied-from providing an attractive venue for official receptions given by the Lord Mayor, the Sheriff and the Vice-chancellor of the University of Bristol to housing a training course for. students for the diploma of the Museums Association.

Departmental reports record valuable work on the coin collections, greatly used for reference purposes, 
new exhibits on African ethnology, primitive shipping, berries and twigs, British Lepidoptera for beginners and metalliferous mining in the Mendip Hills, and a new room devoted to Georgian costume as a contrast to the already popular Victorian room. The now Department of Conservation is proving its great worth and has a lengthy and interesting list of repairs completed, treatments accomplished, models made and exhibits prepared to its credit. Its organization has been greatly helped by the Works Laboratory of the Bristol Aeroplane Company-an interesting example of co-operation. Special reference is due to the work for schools, for which an additional assistant organizer has been appointed. Lessons in history, biology, geology and geography are given to an everincreasing number of classes, and it is gratifying to note that children from nearly one-third of all the junior and secondary schools in Bristol attend, while the School Loan Services, with a better collection than ever before of specimens, models and photographs, are used by more than 70 per cent of the schools in the Bristol area. Teachers in training in seven institutions visit the Museum to learn how best to use museum facilities in their future professional practice. At the other end of the scale, the Saturday Club continues to enjoy an enthusiastic membership of young naturalists aged 9-11 years.

D. A. Allan

\section{SOME PROBLEMS OF SMALL FIRMS}

A SHORT report published by the Department of Scientific and Industrial Research gives details of one of the most encouraging services to industry carried out under its auspices*. It is a commonplace that the economic prosperity of Great Britain would be secure if a fair proportion of the many small firms and medium-sized firms could be brought up to a standard of efficiency equal to that of some of the bigger firms. One of the difficulties is that, hitherto, there has been an unbridged gap between research institutions with their store of valuable knowledge and the small and medium-sized firms who might well use this knowledge but lack trained scientists and technologists to guide them to it. This report describes the work of a technical liaison service which was organized in 1955-56 by the Scottish Council (Development and Industry), the broad purpose of which is to promote the economic development and well-being of Scotland. A team of three investigators, all men who had retired from responsible managerial or technical posts in industry, visited small and medium-sized engineering firms in the industrial belt of Central Scotland to find out what problems confront the smaller firms in the drive for greater efficiency and expansion; what equipment they possess for solving these problems for themselves; where to get help; and in what ways external sources could help.

During the survey the technical liaison service helped 109 firms, each with fewer than five hundred employees and with no elaborate management organization, to find solutions to 223 problems which they could not overcome with their own resources. Every interested firm was visited by a member of the team who helped to define each problem precisely and then to find a solution. Some questions could be answered on the spot from the member's own experience; the rest were referred to the Scottish Council's office in Edinburgh, where the technical co-ordinator of the project got in touch with the most likely sources of information.

The work of the experimental technical liaison service disclosed that :

(1) Firms in the survey were relying predominantly on trade contracts and other firms for information on new developments and techniques, and were accordingly in danger of operating within a closed circle.

* Small Firms with Big Problems : a Short Account of an Experimental Technical Liaison Service run by the Scottish Council (Development and Industry). Pp. iii +24. (London: Department of Scientific and Industrial Research, 1958.)
(2) A few firms had ample technical resources, but most had few or none.

(3) Although many of the firms seemed to be attempting creative adjustments to new circumstances, only ten of them were managing to do so without introducing violent and disruptive changes. There were many reasons for this, but a predominant one was lack of technical information on which long-term plans could be based.

(4) Most firms were having difficulty in answering, from their own resources, some of the problems which affected their future plans; they discussed these with the technical liaison service.

(5) Half the problems had been previously aban. doned, or were defined for the first time during discussions with the team, or with the staff of research and other organizations introduced by them.

(6) Answers to more than 70 per cent of the problems were found by the technical liaison service during the survey. The information roquired was in existence, but its sources unknown to, or unused by, the firms.

The outstanding success of the technical liaison service led the steering committee of the Scottish Council to recommend that a permanent technical liaison service should be provided; at first it would help small and medium-sized engineering firms, as the experimental service had done, but later it should be extended to other industries. The Committee indicated that the operation of regional schemes on these lines should be in the charge of the Department of Scientific and Industrial Research and suggested that the Secretary of State for Scotland should be asked if an official service could be provided. Mean. while, the Committee felt that the service was so urgently needed that it should be run by a private Scottish institution until an official scheme could be established-preferably by an independent organization, like the Royal College of Science and Technology at Glasgow, since the experimental service gained much from the support of technical colleges and from easy access to technically qualified staff with industrial training.

The Scottish Education Department has recently authorized the expenditure required to set up a technical information service, on the lines proposed by the Scottish Council's steering committee, under the Department of Industrial Administration at the Royal College of Science and Technology, Glasgow. This extension of the Department's work is largely experimental and will be revised in not more than three years. 